DEPOSITION AND PROPERTIES OF NOVEL
NITRIDE SUPERLATTICE COATINGS

Progress Report

for September 28, 1990 - Apri1, 1993

S.A. Barnett, W.D. Sproul, and M.S. Wong

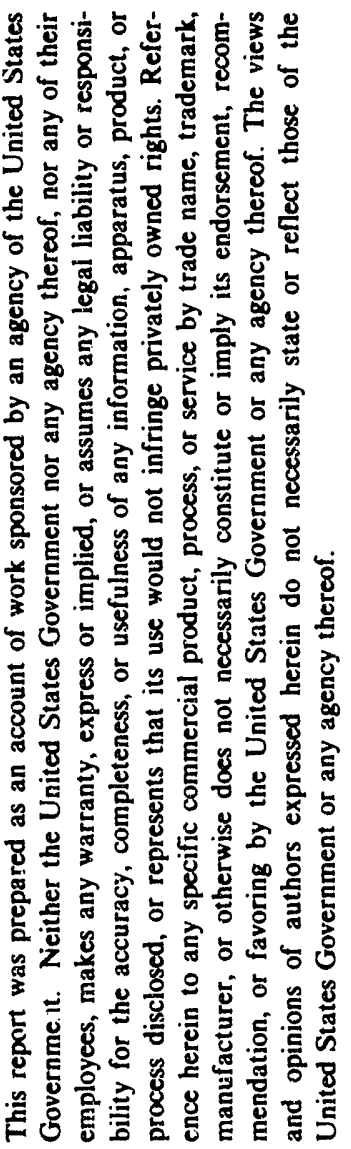

Northwestern University

Evanston, IL 60201

Apri1 1993

Prepared for

The U. S. Department of Energy

Agreement No. DE-FG02-90ER45434 
SUMMARY . . . . . . . . . . . . . . . . . . . . . . 1


DEVELOPMENT OF DEPOSITION SYSTEM EFFECTS OF DEPOSITION PARAMETERS ......................... 2 STUDIES OF INDIVIDUAL LAYER MATERIALS . . . . . . . . . . . . . 9 MECHANISMS OF HARDNESS ENHANCEMENT . . . . . . . . . . . . . . . 10 PUBLICATIONS, PRESENTATIONS, PATENT AND TECHNOLOGY TRANSFER . . . . . . 11 REFERENCES ............................. 12 


\title{
DEPOSITION AND PROPERTIES OF NOVEL NITRIDE SUPERLATTICE COATINGS
}

\begin{abstract}
SUMMARY
We have carried out detailed studies of the processing, structure, and properties of certain polycrystalline superlattice coatings, including $\mathrm{TiN} / \mathrm{NbN}, \mathrm{TiN} / \mathrm{VN}, \mathrm{TiN} / \mathrm{Ni}$, and $\mathrm{TIN} / \mathrm{NiCr}$, which were produced using an opposed, dual-cathode, high-rate, reactive, unbalanced-magnetron sputtering system. The coatings exhibited hardness values as high as $5200 \mathrm{kgf} / \mathrm{mm}^{2}$ for $\mathrm{TiN} / \mathrm{NbN}$, 5100 for $\mathrm{TIN} / \mathrm{VN}, 3500$ for $\mathrm{TIN} / \mathrm{Ni}$, and 3200 for $\mathrm{TiN} / \mathrm{NiCr}$. These hardness values are all twice higher than their corresponding rule-of-mixture hardness values. The structure and properties of the coatings are a strong function of period, the partial pressure of $\mathrm{N}_{2}$, and the energy and flux of ion bombardment during deposition. The possible mechanisms for hardness enhancement in the polycrystalline superlattice appear to be a result of dislocation blocking due to coherency strains, a difference in dislocation line energies between the layers, and the small grain sizes observed in the superlattices. Hcivever, which mechanism dominates the hardness enhancement is still under investigation. In response to the high interest shown by industries in using the coatings, BIRL formed a 2-year Industrial Group Program, currently with 12 members, to transfer the superlattice coating technology. It therefore seems likely that in an extremely short time this DOE funded basic research will result in commercial applications.
\end{abstract}

\section{INTRODUCTION}

We have demonstrated that the high hardness values previously observed in single-crystal nitride superlattices can be reproduced in polycrystalline nitride/nitride and nitride/metal superlattices, which are composed of alternating thin layers of different materials. The thicknesses of the two neighboring iayers (period) were between 3 and $150 \mathrm{~nm}$ for the nitride/nitride systems and between 1 and $74 \mathrm{~nm}$ for the nitride/metal systems, and they were determined by the rotating speed of the substrate holder and the sputtering rate of the individual materials. The polycrystalline superlattice coatings 
are very hard and have a definite compositional modulation. Various analytical techniques were used to characterize the mechanical properties, structure, and composition of the films and to understand the possible strengthening mechanisms in these polycrystalline superlattices. The detailed results achieved in this program are shown in the Section of publications, presentations, patent and technology transfer, and in the Appendixes $A$ and $B$. The following sections summarize the most important results from the initial work.

\section{DEVELOPMENT OF THE DEPOSITION SYSTEM AND PROCESS}

The deposition of the polycrystalline superlattice films was carried out in a unique opposed-cathode unbalanced-magnetron sputtering system that has been described in detail elsewhere. ${ }^{1-4}$ The magnetrons were highly unbalanced ${ }^{5}$ by using strong NdFeB magnets in the outer pole positions and AlNiCo magnets in the inner pole positions to provide high ion fluxes at the depositing film surface during bias sputtering.

To use the opposed magnetron system to deposit polycrystalline superlattice coatings in a one-step process, two major issues were resolved. First, control of the partial pressure of nitrogen in front of each target to form the desired composition and structure of the individual coating was achieved by using an automatic feedback control loop, which consists of a differentially pumped quadrupole mass spectrometer system and a master/slave nitrogen mass-flow controller. Second, elimination of line-of-sight target cross contamination and the reduction of gas-scattering effects which cause atomic intermixing between layers was achieved using a substrate holder which is wider than the target.

\section{EFFECTS OF DEPOSITION PARAMETERS}

The properties of nitride films prepared using reactive sputtering are different from the corresponding bulk materials in terms of crystal structure, lattice parameters, residual stress, preferred orientation, chemical composition, grain size, and defect structure. These structural properties in turn are determined by the characteristics of the deposition systems and the process parameters such as target power, substrate bias, nitrogen partial pressure, total gas pressure, and substrate temperature. In this study, three 
deposition parameters were explored in detail, and the results indicate that the hardness values of polycrystalline superlattices were dependent not only on superlattice period, but on process parameters such as nitrogen partial pressure and substrate bias. The deposited films were characterized using various techniques to determine their hardness, thickness, adhesion strength, composition, and crystal structure.

Effect of Superlattice Period Figure 1 shows the hardness (Vickers hardness, $H v$ ) values of TiN/VN and TiN/NbN superlattice films as a function of the superlattice period, $\lambda$. Initially the hardness increases rapidly with increasing $\lambda$, reaches maximum values of 5100 and $5200 \mathrm{kgf} / \mathrm{mm}^{2}$ at $\lambda=5 \mathrm{~nm}$ for TiN/VN and NbN/TiN, respectively, before decreasing with increasing values of 1. This dependence may be explained as follows. First, intermixing effects during deposition become more pronounced as the layers are made thinner, leading, in the limit of very thin layers, to an alloy with low hardness. second, the layer interfaces become increasingly incoherent as $\lambda$ is increased, such that coherency strain hardening is lost.

Figure 2 shows cross-sectional TEM micrographs of a TiN/NbN superlattice film with a period of $8 \mathrm{~nm}$. The light-color layers are TiN and the dark ones are $\mathrm{NbN}$. The pronounced contrast differences between the layers indicate the presence of a strong composition modulation. The graphs show that the interfaces between layers are rough, but they seem to be coherent across the interface. The grain sizes seem to be smaller than the period, and most of the grains are crystalline.

For the cases of $\mathrm{TiN} / \mathrm{Ni}$ and $\mathrm{TiN} / \mathrm{Ni}_{0.9} \mathrm{Cr}_{0.1}$, the dependence of $\mathrm{HV}$ on $\lambda$ is different from that of TiN/NBN and TiN/VN. As shown in Figure 3 for TiN/NiCr, the hardness decreased monotonically with increasing $\lambda$ with the smallest $\lambda$ explored, $1.2 \mathrm{~nm}$, giving the highest hardness. The difference may be due to the fact that $\mathrm{Ni}$ and $\mathrm{TiN}$ are not miscible allowing very thin layers without intermixing. The evidence can be seen in Figure 4, where shows the low-angle $X$-ray diffraction (XRD) patterns of TiN/NiCr superlattices with four different periods. Up to 8th-order diffraction peaks for the sample with a period of $7.4 \mathrm{~nm}$ and one peak for the sample with a period of $1.9 \mathrm{~nm}$ were observed, indicating a well defined structure modulation. While $\mathrm{Ni}$ and TiN are the most stable phases, the formation of $\mathrm{Ni}-\mathrm{Ti}$ intermetallics may occur in very thin layers. The cr.emical modulation may not be continuous, but distinct grains of two separate phases of nitride and metal may still exist in the film. A reduction in grain size as $\lambda$ is decreased was observed in $\mathrm{TiN} / \mathrm{NiCr}$ by both 




Figure 1. Vickers microhardness values of TiN/VN and TiN/NbN superlattices as a function of the superlattice period.



Figure 2. Cross-section TEM micrograph for a TiN/NbN superlattice film with a period of $8 \mathrm{~nm}$. The light-color layers are TiN and the dark one are $\mathrm{NbN}$. 




Figure 3. Microhardness of the TiN/NiCr superlattices, with $1_{\text {NiCr }} /$ period $=0.4$, as a fuction of period.



Figure 4. Low-angle XRD patterns for $\mathrm{TiN} / \mathrm{NiCr}$ superlattices with period $=$ $1.9,2.2,3.9$, and $7.4 \mathrm{~nm}$, respectively. 
plan-view and cross-sectional TEM as shown in Figure 5 . Thus, the small grain size may contribute to the hardness of the metal/nitride system.

High-angle XRD and Auger analys is of the superlattices also showed the structural and compositional modulation. In the XRD analysis of TiN/NbN and TiN/VN, the most intense peaks correspond to the average interplanar spacing of alloy (111) and (200) planes. Satellites peaks around main peaks were observed for $\mathrm{TiN} / \mathrm{NbN}$, but not for $\mathrm{TiN} / \mathrm{VN}$. This is due to the similar $x-$ ray scattering factors of $\mathrm{TiN}$ and $\mathrm{VN}$, which leads to minimal scattering from the composition modulation and hence very weak superlattice peaks.

Nitrogen Partial Pressure Figure 6 shows the hardness values versus nitrogen partial pressure $\left(P_{\mathrm{N} 2}\right)$ for TiN/VN superlattice films. For these data, the period was $8 \mathrm{~nm}$, total pressure was $8 \mathrm{mTorr}$ and substrate bias was $-100 \mathrm{~V}$. A peak hardness of $4500 \mathrm{kgf} / \mathrm{mm}^{2}$ was obtained at $P_{N 2}=2.0 \times 10^{-4}$ Torr. XRD analysis showed that both $\mathrm{TiN}$ and $\mathrm{VN}$ had a cubic $\mathrm{NaCl}$-type structure.

$P_{\mathrm{N} 2}$ is one of the dominant process parameters affecting the formation of the phases and the stoichiometry of sputtered nitride films. To study the effect of $P_{\mathrm{N} 2}$, flow vs. partial pressure hysterisis curves for individual target materials was obtained first. It was found that the $P_{N 2}$ needed to form the desired stoichiometric cubic phase for $\mathrm{Nb}$ was twice that for Ti. Studies to optimize the flow-rate-ratio for the $\mathrm{Ti}$ and $\mathrm{Nb}$ targets have been carried out, and the optimized ratio was found to be $1: 2$. In the cases of TiN/VN, TiN/Ni and $\mathrm{TiN} / \mathrm{NiCr}$, the optimized ratios were $1: 1,1: 0$, and $1: 0$, respectively.

Substrate Bias Figure 7 shows the Vickers hardness and scratch adhesion critical load (LC) for the adhesion of TiN/VN superlattice films deposited with different substrate bias (Vs) values, with a period of $8.2 \pm 1.0 \mathrm{~nm}$. The film thickness was 4-5 $\mu \mathrm{m}$ after a 60 minute deposition. The Lc values for films deposited with $V_{s}=-50 \mathrm{~V}$ are as high as $10 \mathrm{kgf}$, but the critical load drops below $4 \mathrm{kgf}$ as $V_{s}$ is increased to $-150 \mathrm{~V}$. The hardness values reach a maximum value at about $-150 \mathrm{~V}$ and begin to drop as the substrate bias increases further. A similar effect of substrate bias on coating hardness and adhesion was also found in $\mathrm{TiN} / \mathrm{NbN}$. Similar dependence, al though with much lower absolute values have been observed for homogeneous nitrides.

Ion bombardment during bias-sputter deposition of superlattice coatings can affect the film composition modulation, defect densities, and porosity, and it 


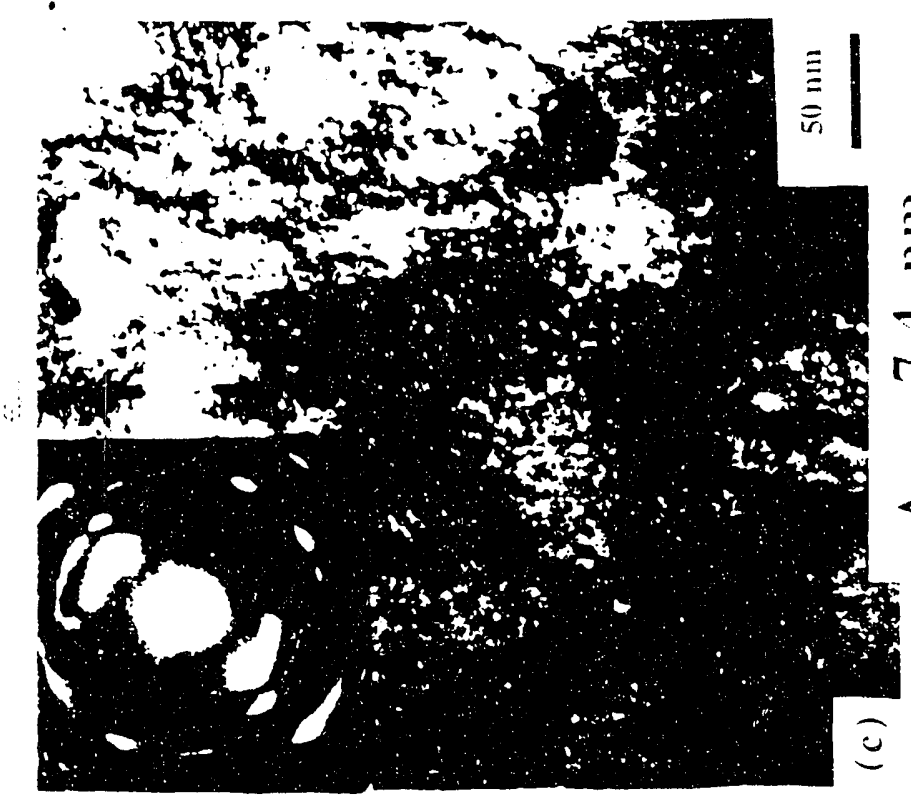

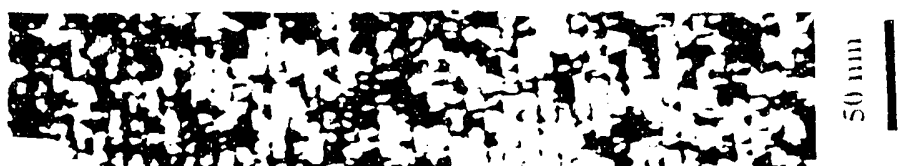

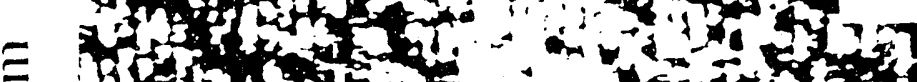

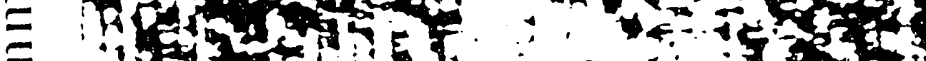

ifort:

1.

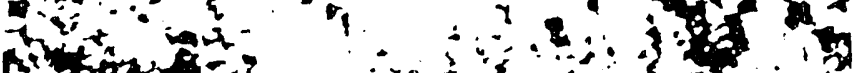

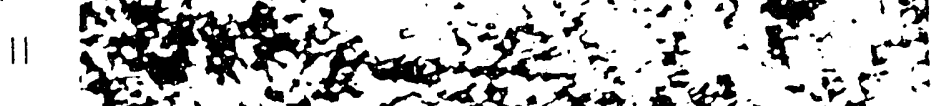

$<$ cotar

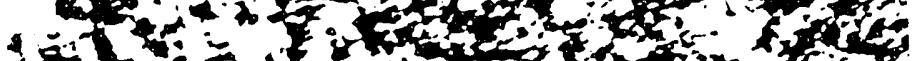

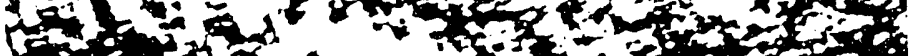

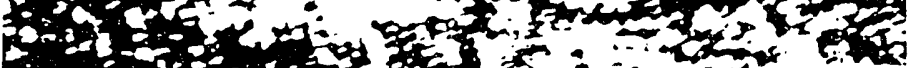
$\therefore-0-000$

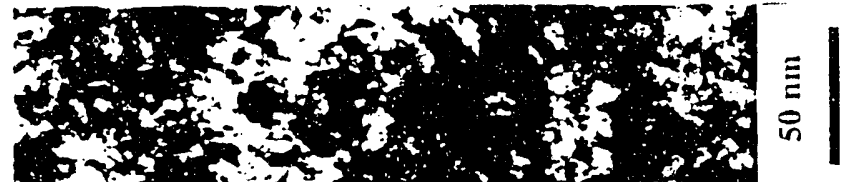








intions

12

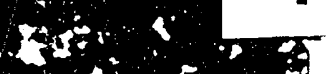













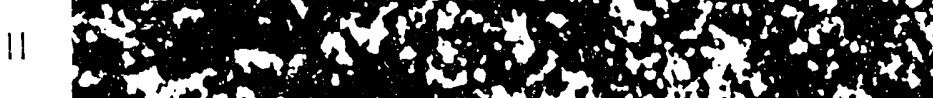



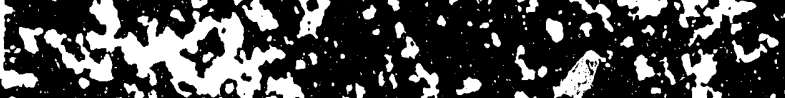



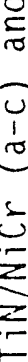

0

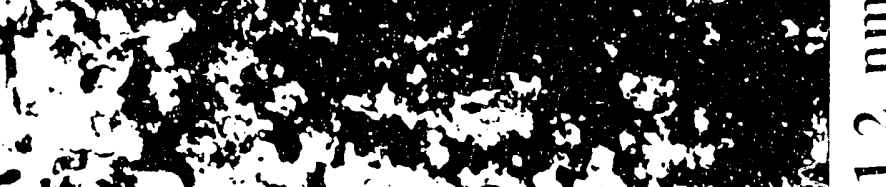

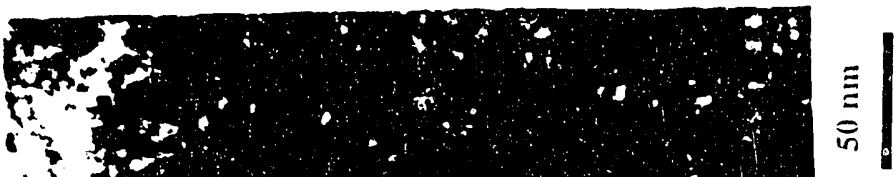

$\approx \cong$

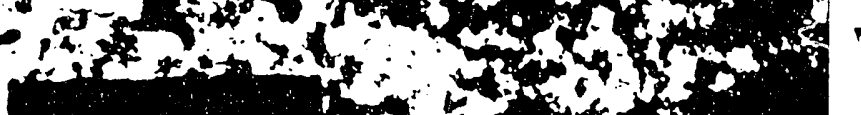
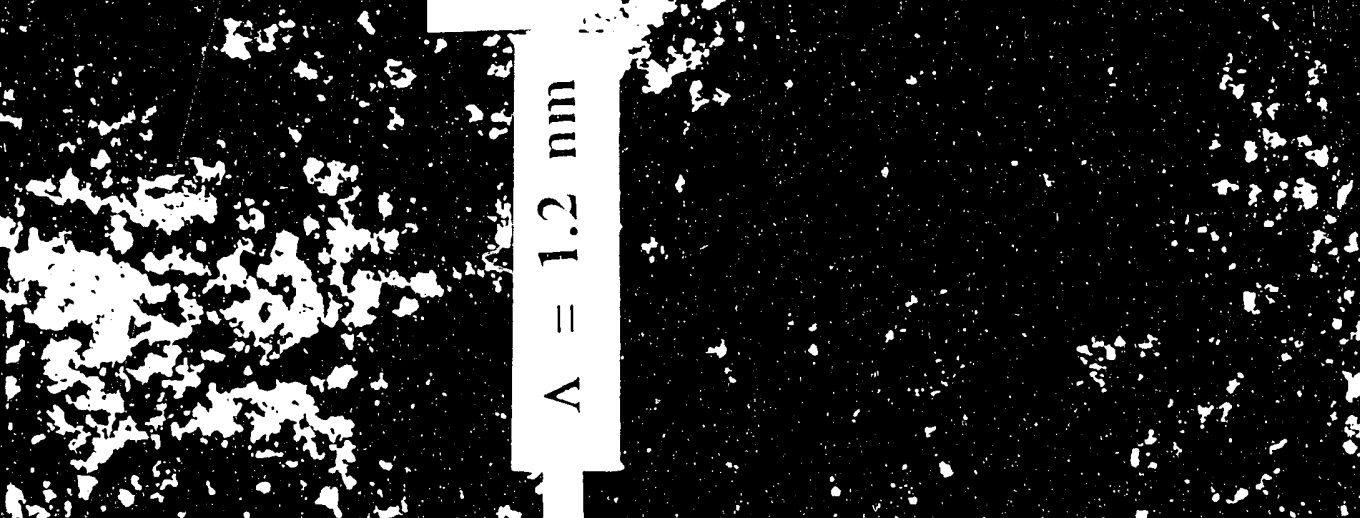

$10^{4}+0^{4}+4$

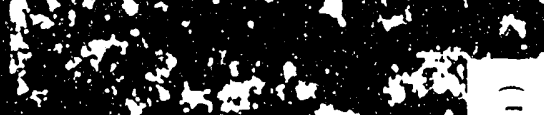

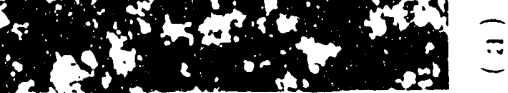
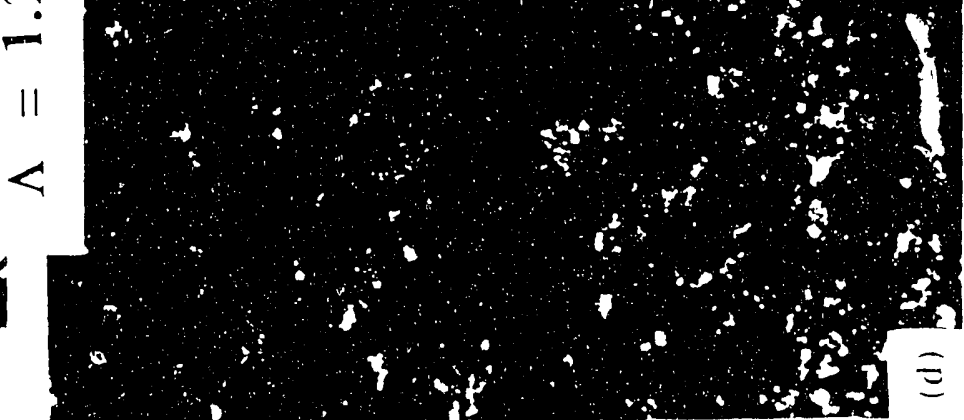


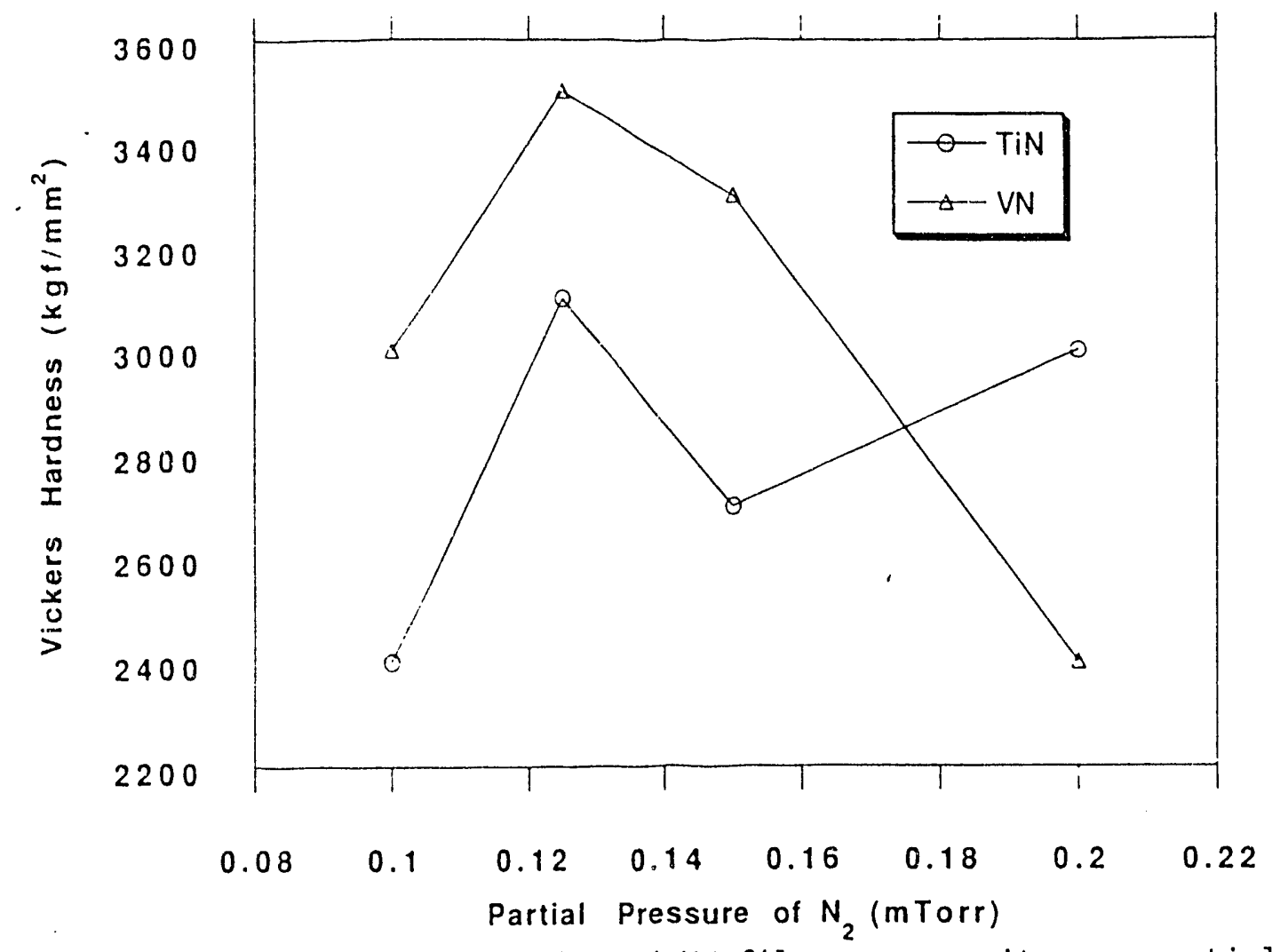

Figure 6. Microhardness of $T i N$ and $V N$ films versus nitrogen partial pressure, $P_{\mathrm{N} 2}$. The films were deposited with the substrate holder in stationary mode and at a total pressure of 6 mTorr and a substrate bias of $-100 \mathrm{~V}$.

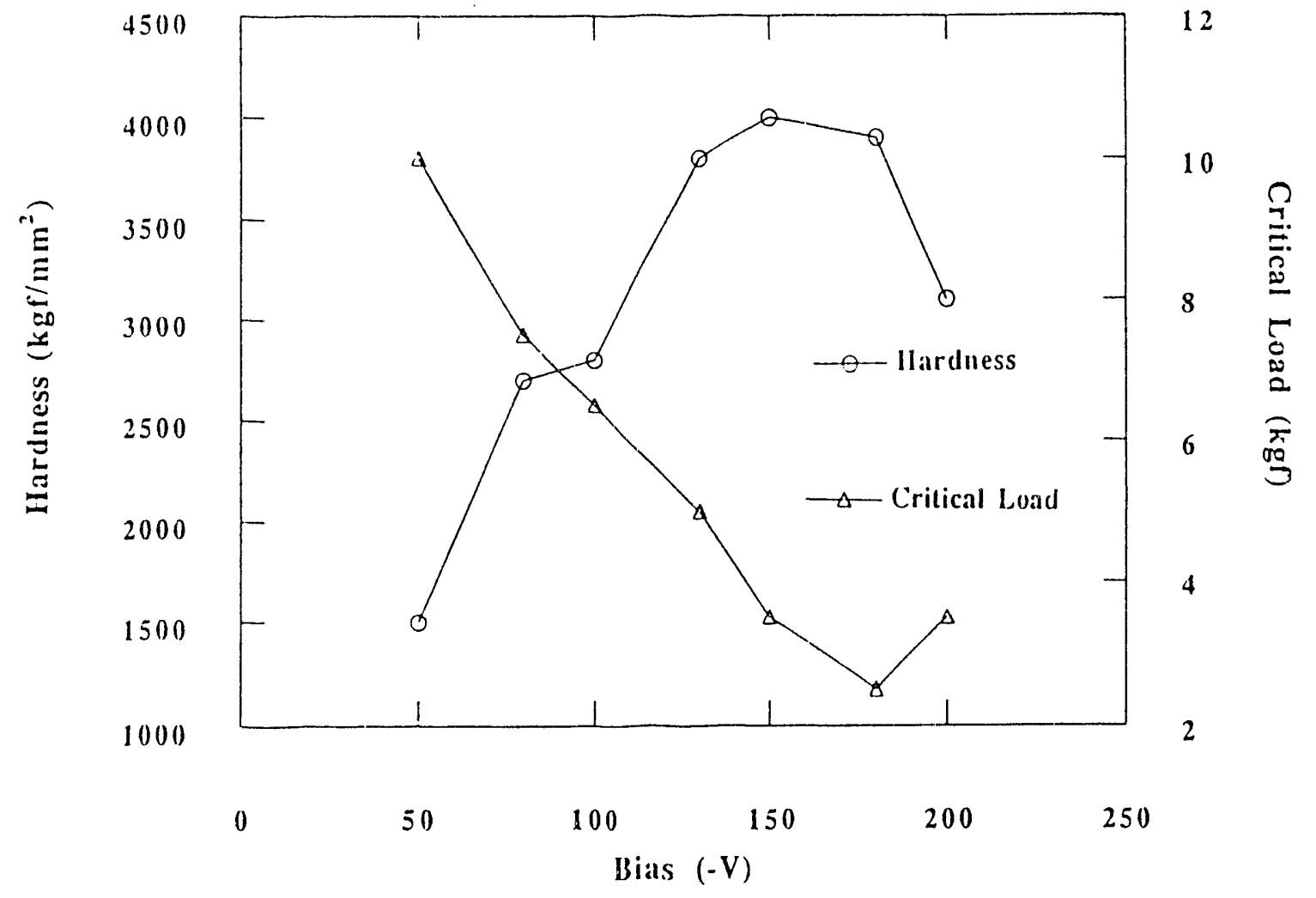

Figure 7. Microhardness and scratch adhesion critical load of TiN/VN superlattice films versus substrate bias voltage. The films were deposited with a period of $8.2 \pm 1.0 \mathrm{~nm}$ and at $P_{\mathrm{N} 2}=1.25 \times 10^{-4}$ Torr. 
can also lead to compressive stress in the film. Thus, proper energy levels and flux of ion bombardment during coating deposition are critical to enhance coating hardness.

\section{STUDIES OF INDIVIDUAL MATERIALS}

The results on the effect of deposition parameters on polycrystalline superlattice structure, hardness, and adhesion are analogous to the dependence observed for polycrystalline homogeneous nitrides such TiN, NbN, and $V N .^{6-9}$ The primary differences between homogeneous nitrides and superlattices is quantitative. The hardness and adhesion values obtained under optimal conditions are much higher for the superlattices. Thus, in order to obtain polycrystalline superlattice coatings with the desired properties, the individual layer materials need to be optimized first.

To understand the structure and properties of individual layer materials, detailed studies of sputter deposition of monolithic niobium nitride films were also carried out. The high-rate reactive magnetron sputtering process was used to deposit niobium nitride films. Despite the complexity shown in phase diagram for $\mathrm{Nb}-\mathrm{N}$, only three different crystalline phases, $\mathrm{Nb}$ metal, cubic $\delta-\mathrm{NbN}$, and hexagonal $\delta^{\prime}-\mathrm{NbN}$, were observed in the parameter space explored by sputtering a niobium target in an atmosphere of argon and nitrogen. The effects of three deposition parameters including nitrogen partial pressure, target power, and substrate bias voltage were explored. All the deposition parameters affected the formation of the different phases with regard to the preferred orientation, and the relative amount of each phase formed, which, in turn, affected the properties of the coatings. The hardness of these reactively sputtered niobium nitrides ranges between 1700 and 4100 $\mathrm{kgf} / \mathrm{mm}^{2} \mathrm{HV}_{0.025}$. The highest hardness is significantly higher than the reported hardness value, $1400 \mathrm{kgf} / \mathrm{mm}^{2}$, for bulk niobium nitride. The primary factor for the hardness increment is due to the effects of low energy ion bombardment during film growth, based on previous studies in our group and elsewhere. 


\section{MECHANISMS OF HARDNESS ENHANCEMENT}

The major mechanisms proposed to explain the hardness enhancement in single crystal superlattices are the effects of coherency strain and dislocation line energy differences. In the cases of polycrystalline superlattices, the effects of grain size and defect structure induced by ion bombardment can also affect film hardness. The dependence of hardness on the superlattice period (see Figure 1) is remarkably similar to that reported previously for singlecrystal TiN/VN and TiN/NbN. Both the optimal value for the superlattice period, 5-6 nm, and the maximum hardness, over $5000 \mathrm{kgf} / \mathrm{mm}^{2}$, were nearly the same in both cases. This suggests that the factors controlling hardness for polycrystalline superlattices are similar to the single-crystal case.

However, previous work on polycrystalline $\mathrm{Ta} / \mathrm{TaC}$ layered structures suggested that the film grain size, which tended to be limited by the layer thickness, controlled the hardness. ${ }^{10}$ A recent study of $\mathrm{Ti} / \mathrm{Ti}-\mathrm{N}, \mathrm{HF} / \mathrm{HF}-\mathrm{N}$, and $\mathrm{W} / \mathrm{W}-\mathrm{N}$ multi-layer films with hardness values as high as $5000 \mathrm{kgf} / \mathrm{mm}^{2}$ also suggested this same relationship. ${ }^{11}$ Synthesis and processing of nanophase materials are emerging in many areas of materials science. Nanophase materials, having 5 to $50 \mathrm{~nm}$ grain sizes often possess properties that are rather different from the ir coarser-grained counterparts due to the fact that a large fraction of atoms is situated on grain boundaries. Grain size refinement often increases strength and hardness according to the Hall-Patch relationship. Our current study has shown that the hardness of polycrystalline superlattices is a strong function of superlattice period, substrate bias, and nitrogen partial pressure, which all affect the grain size of resulting films. Grain size effects almost certainly play an important role in the hardness enhancements of polycrystalline superlattices.

In order to understand the strengthening mechanisms in polycrystalline superlattices, further experiments must be designed to separate the various contributing causes, as described in our renewal proposal. Experiments with selected new superlattice constituents should be carried out to allow separation of coherency-strain, dislocation-line-energy, and grain-size effects. Because of the interdependency of several processing conditions on film properties, our approach in the future will include statistical experimental design methods to better define the optimal processing conditions. 


\section{PUBLICATIONS, PRESENTATIONS, PATENT AND TECHNOLOGY}

Several publications and presentations and one patent application have already resulted from this program as listed below. In addition, in response to hundreds of inquiries from R\&D laboratories and industries and subsequently to a meeting at BIRL with attendees representing 45 companies from a wide range of industries, BIRL has formed an Industrial Group Program, currently with 12 industrial members, to transfer and to commercialize the superlattice coating technology. The detailed description of the group program can be found in the attached documents. We believe this group program will very likely result in commercial use of superlattice coatings within 3-4 years. Continued DOE support of the basic research aspects of these systems is crucial to this very rapid commercialization effort.

1. X. Chu, M.S. Wong, W.D. Sproul and S.A. Barnett, "Mechanical Properties and Microstructures of Polycrystalline Metal/Ceramic Superlattices:

$\mathrm{TiN} / \mathrm{Ni}$ and TiN/NiCr", paper submitted, to be presented at Int. Conf. in Metallurgical Coatings and Thin Films (ICMCTF), 1993.

2. M.S. Wong, W.D. Sproul, X. Chu, and S.A. Barnett, "Reactive Magnetron Sputter Deposition of Niobium Nitride Films", presented at American Vacuum Society (AVS) 39th National Symposium and Topical Conf rences, Chicago, 1992. paper in press, J. Vac. Sci. Technol. A, July (1993).

3. X. Chu, M.S. Wong, W.D. Sproul, and S.A. Barnett, "Superhard Nanocompcsite of Nitride Superlattices Formed by Unbalanced Magnetron Sputtering", presented at AVS 39th Annual Meeting, Chicago, 1992.

4. X. Chu, M.S. Wong, W.D. Sproul and S.A. Barnett, "Superhard Nanocomposite of Nitride Superlattices Formed By Unbalanced Magnetron Sputtering", presented at Materials Research Society (MRS) Annual Meeting, Dec. 1992, paper in Nanophase and Nanocomposite Materials, MRS Symposium proceedings V.286, (1993) 379-384.

5. X. Chu, M.S. Wong, W.D. Sproul and S.A. Barnett, "Reactive Unbalanced Magnetron Sputter Deposition of Polycrystalline TiN/NbN Superlattice Coatings", Presented at ICMCTF 92, paper in press, Surf. and Coatings Tech. April (1993).

6. X. Chu, M.S. Wong, W.D. Sproul and S.A. Barnett, "Deposition and Properties of Polycrystalline TiN/NbN Superlattices Coatings", presented at AVS 38th Annual Meeting, Seattle, 1991. paper published in J. Vac. Sci. Technol. A, 10(4) (1992) 1804-9.

7. S.A. Barnett, W.D. Sproul, M.S. Wong, and X. Chu, "Polycrystalline Superlattices, Coated Substrate and Method/Apparatus for Making Same", U.S. patent application filed on Nov. 9, 1992. 


\section{REFERENCES}

1. X. Chu, M. S. Wong, W. D. Sproul, S. L. Rohde and S. A. Barnett, J. Vac. Sci. Technol., A 10 (4), 1604 (1992).

2. X. Chu, M.S. Wong, W.D. Sproul, and S.A. Barnett, in press, Surface and Coating Tech., April 1993.

3. X. Chu, M.S. Wong, W.D. Sproul and S.A. Barnett, "Superhard Nanocomposite of Nitride Superlattices Formed By Unbalanced Magnetron Sputtering", in press, in Nanophase and Nanocomposite Materials, MRS Sym. proceedings V.286, 1993.

4. X. Chu, M.S. Wong, W.D. Sproul and S.A. Barnett, "Mechanical Properties and Microstructures of Polycrystalline Metal/Ceramic Superlattices: $\mathrm{TiN} / \mathrm{Ni}$ and $\mathrm{TiN} / \mathrm{NiCr}$ ", paper submitted, to be presented at Int. Conf. on Metallurgical Coatings and Thin Films (ICMCTF), 1993.

5. W. D. Sproul, P. J. Rudnik, M. E. Graham, and S. L. Rohde, Surface and Coating Technology, 43/44, 270 (1990).

6. W. D. Sproul, P. J. Rudnik, and C. A. Gogol, Thin Solid Films, 171, 171 (1989).

7. W. D. Sproul, P. J. Rudnik, and M. E. Graham, Surface and Coatings Technology, 39/40, 355 (1989).

8. M.S. Wong, W.D. SprouT, X. Chu, and S.A. Barnett, "Reactive Magnetron Sputter Deposition of Niobium Nitride Films", in press, J. Vac. Sci. Technol. 1993.

9. G. Farges, E. Beauprez and D. Degout, Surface and Coatings Technology, 44/45, 115 (1992).

10. R.W. Springer, N. L. Ott and D. S. Catlett, J. Vac. Sci. Technol., A 4 (16), 878 (1979).

11. K.K. Shih and D.B. Dove, Appl. Phys. Lett. 61 (6), 654 (1992). 

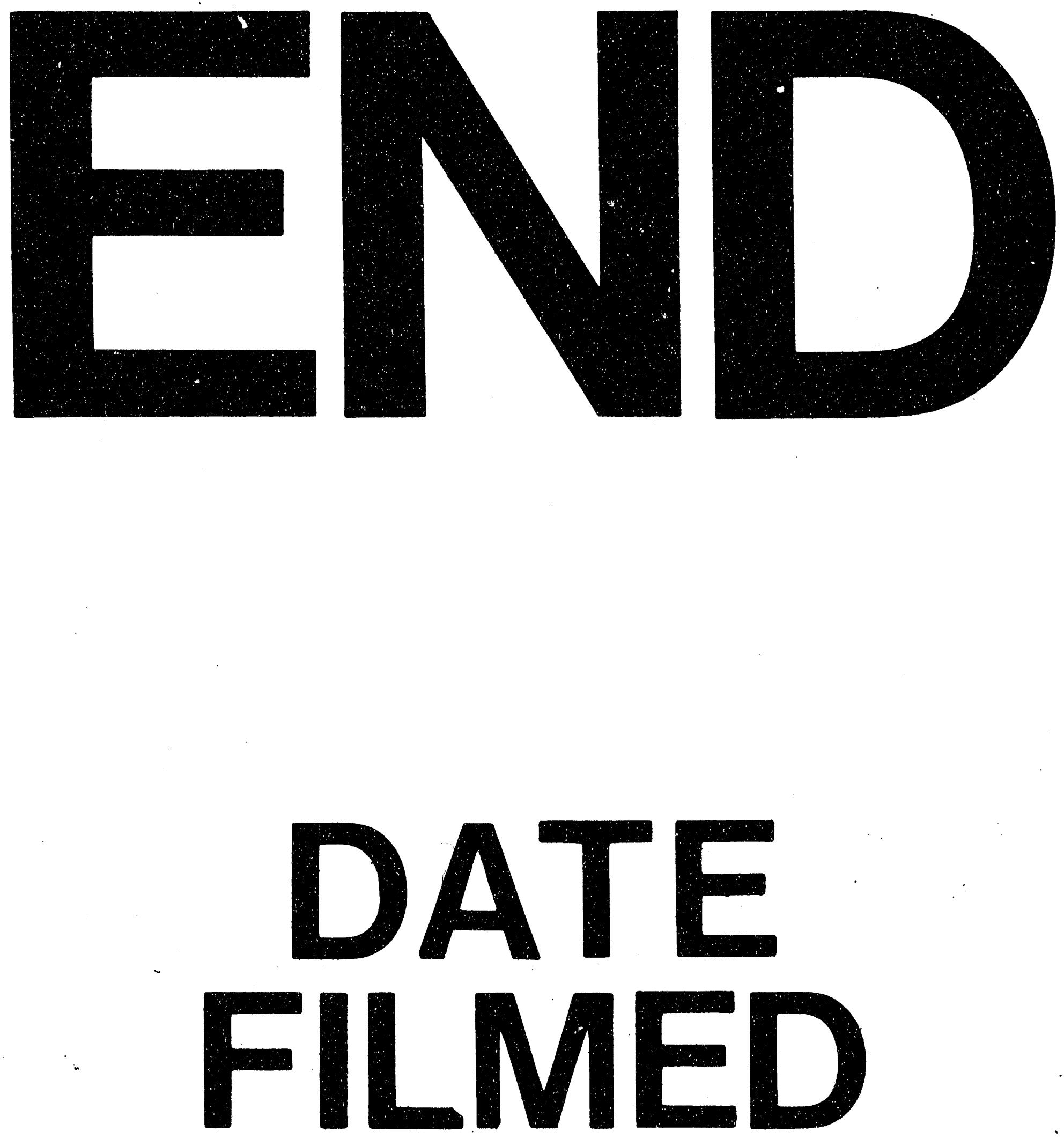

)

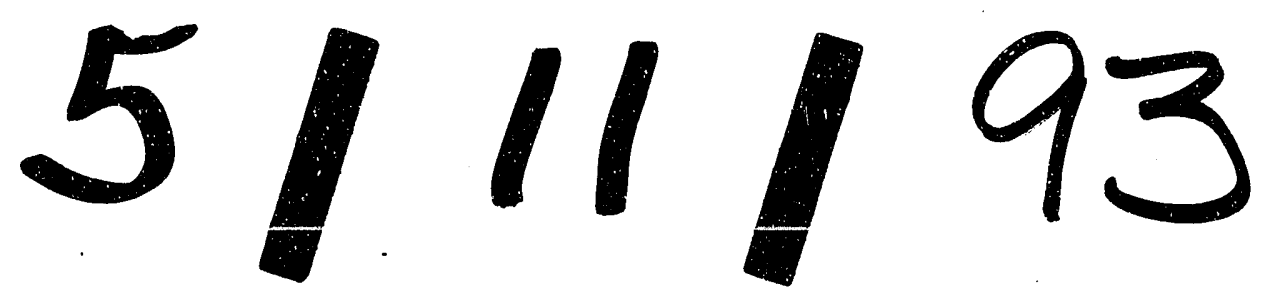


